\title{
Project and Management Monitoring System Survey Drawing Inventory Unit Survey Production Tools in PT Telkom Akses Samarinda
}

\author{
Siti Qomariah \\ Computer Engineering, STMIK \\ Widya Cipta Dharma, Samarinda, \\ 75123 \\ sitiqom@wicida.ac.id
}

\author{
Basrie \\ Information System, STMIK \\ Widya Cipta Dharma, \\ Samarinda, 75123, Indonesia \\ basrie@wicida.ac.id:
}

\author{
Erfanie Mahmud* \\ Information System, STMIK \\ Widya Cipta Dharma, Samarinda, \\ 75123, Indonesia \\ *Corresponding author
}

\begin{abstract}
Project Monitoring System and Production Equipment Management Survey Drawing Inventory Unit at PT Telkom Akses Samarinda is a system intended for SDI units because SDI units are directly related to the project and production equipment of the Telkom Group. Where on this system has several users based on their level. This system was built because so far, the system applied was still quite manual, namely a collection of online spreadsheets on Google Drive, where files with each other were still not connected so that when there was a change, not all data was connected even though the data was related. Also, the advantage of this system is that management can directly monitor a project from the Optical Distribution Point (ODP) booking process to the ODP that can be sold in the field. Project Monitoring System and Production Equipment Management Survey Unit Inventory Survey Unit PT Telkom Akses Samarinda was developed with Waterfall system development methods, data collection methods by interviewing, observing and studying literature, analyzing system design using UML (Unified Modeling Language). The method of testing the Monitoring System and Inventory Equipment Production uses the Blackbox testing method. With this system of monitoring and inventory of production equipment, the performance of the SDI unit as the Administrator is faster because all this time the inventory processing process is still utilizing the number of online spreadsheet files on Google Drive, while with this system all work has been systemized. Fast data search without having to open existing spreadsheet files and
\end{abstract}

Keywords - Monitoring System, Production Equipment Management, Survey Production Tools, Telkom Akses

\section{INTRODUCTION}

PT Telkom Akses Samarinda Area is one of the companies engaged in the field of construction services and management of fiber optic-based network infrastructure, where PT Telkom Akses has production equipment (ALPRO) in the field including Optical Line Termination (OLT), Optical Distribution Frame (ODF), Optical Distribution Cabinet (ODC), and Optical Distribution Point (ODP). PT Telkom Akses Samarinda Area has one unit called Survey, Drawing, and Inventory (SDI), this unit works in the realm of surveying an area that will later be used as optical fiber-based network distribution, redrawing the results of field surveys into a system called Small World whose license is owned directly by Telkom Group in order to adjust ALPRO data available in the field, whether planned or in-service, and also inventory ALPRO data resulting from re-image integration in the Small World application into the Unified Inventory Management (UIM) application, as well as the Telkom Group's ALPRO data warehouse so that it is not uncommon for technicians in the field to ask about information on an ALPR to the SDI unit. The things that are often asked by technicians include the coordinates of an ODP or ODC, panel data or mancore of an ODP in ODC, the distribution path of an ODP, etc.

Although it already has several supporting applications such as Small World and UIM, in fact the SDI unit is also still difficult and long enough to answer the questions that are often asked by technicians, so the SDI unit also stores all these data in a collection of spread sheet files on Google Drive. When implementing Google Drive as a solution, it turns out that there are new problems that arise, namely not connecting one file to another, for example the ODP coordinate information is not a file with the ODP panel data information, so when the technician questions the coordinates and panel of an ODP automatically there are two file that is opened, so the authors feel the effectiveness of the system that is currently running.

\section{LITERATURE REVIEW}

The materials and methods used in this system include: A. System

According to Sutabri (2012), simply put, a system can be interpreted as a collection or set of elements, components, or variables that are organized, interact with each other, are interdependent, and integrated.

According Jogiyanto (2008), the system can be defined by the procedure approach and with the component approach. With a procedural approach, the system can be defined as a collection of processes that have specific objectives. Whereas with the component approach, the system can be defined as a collection of components that are interconnected with one another to form a unity that achieves certain goals.

So the system is a structure that is designed with specific objectives that produce input and output by approaching the component. 


\section{B. Inventory System}

Inventory system is a set of policies and controls, which monitor inventory levels, and determine which levels must be maintained, when stocks must be replenished and how much to order (Assauri, 2016: 225).

The inventory system will provide the possibility of organizational structure and production operation policies, to maintain and supervise goods to be stocked. With this inventory system, management is expected to be responsible for ordering and receiving ordered goods. This can be done by monitoring the time of placing the order, and maintaining or overseeing the path of what was ordered, as well as how many items were ordered and from whom the vendor (Assauri, 2016: 225).

\section{Monitoring}

According to Rai (2008), Monitoring is a condition where the entire organizational control system must be monitored to assess the quality of the control system.

According to Government Regulation No. 39 (2006), monitoring is an activity of closely observing a condition or condition, including certain behaviours or activities, with the aim that all input data or information obtained from the results of these observations can be the basis for making decisions on further actions required.

According to Amsler (2009), there are several monitoring objectives. The purpose of monitoring can be viewed from several aspects, for example the object and subject matter being monitored, as well as the results of the monitoring process itself. The several objectives of monitoring are:

1. Ensure that a process is carried out according to applicable procedures. Thus, the process runs according to the path provided (on the track).

2. Provides a high probability of data accuracy for monitoring actors.

3. Identify unwanted results in a process quickly (without waiting for the process to finish).

4. Develop positive motivation and habits of workers.

\section{The Web}

According to Simarmata (2010), the Web is a system with information presented in the form of text, images, sounds, etc. stored on an internet web server that is presented in the form of hypertext.

According to Arief (2011), the Web is one application that contains multimedia documents (text, images, sound, animation, and video) in it that uses the HTTP protocol (hypertext transfer protocol) and to access it using software called a browser.

Based on the opinions expressed above, it can be concluded that the website is a place on the internet, which presents information in a variety of data formats such as text, images, animation, sound, even video and can be accessed using a variety of client applications to enable the presentation of more interesting information. and dynamic with organized management.

\section{E. Database}

According to Prasetio (2012), a database is a collection of information stored on a computer that is systematic. The main storage place for a database is called a table.

According to Jogiyanto (2009), a Database is a collection of data that are interconnected with one another, stored on computer hardware and used to manipulate software.

Based on some of the opinions stated above, it can be concluded that the database is a collection of information stored in a computer systematically so that it can be checked using a computer program to obtain information from the database.

\section{F. $P H P$}

According to Arief (2011), PHP (PHP: Hypertext Preprocessor) is a server-side scripting language that integrates with HTML to create dynamic web pages. Because it is a server-side scripting the syntax and PHP commands will be executed on the server then the results are sent to the browser in HTML format.

According to Oktavian (2010), PHP is an acronym for Hypertext Pre-processor, which is a programming language containing codes (scripts) that are used to process data and sends it back to the web browser into HTML code.

According to Anhar (2010), PHP stands for PHP: Hypertext Pre-processor, which is a server-side web programming language that is open source. PHP is a script that is integrated with HTML and resides on a server (server side HTML embedded scripting). PHP is a script that is used to create dynamic pages. Dynamic means the page to be displayed is created when the page is requested by the client. This mechanism causes the information received by the client to be always up to date. All PHP scripts are executed on the server where the script is run.

Based on the opinions stated above, it can be concluded that PHP is a scripting language that can be embedded or inserted into HTML.

\section{G. $M y S Q L$}

According to Nugroho (2010), MySQL (My Structured Query Language) is a database creation and management program or often referred to as a DBMS (Database Management System). Another advantage of MySQL is that it uses the standard SQL (Structured Query Language) query language. SQL is a structured request language.

According to Madcoms (2010), MySQL is flexible data storage and fast access is needed in an interactive and dynamic website. The database itself functions as a reservoir of data that you input through the website form. Moreover, it can also be reversed by displaying data stored in a database into a web page. A very popular type of database that is used on many websites on the internet as a data bank is MySQL. MySQL uses SQL and is free, besides that MySQL can run on various platforms, including Linux, Windows, and so on.

According to Arief (2011), MySQL is a very wellknown type of database server and is widely used to build 
web applications that use databases as sources and manage their data.

Based on the opinions stated above, it can be concluded that MySQL is a type of database server that uses SQL as the basic language for accessing its database. MySQL includes the type of RDBMS (Relational Database Management System). That's why terms like tables, rows and columns are used in MySQL. In MySQL, a database contains one or a number of tables. The table consists of a number of rows and each row contains one or several columns.

\section{H. Phpmyadmin}

According to Nugroho (2010), PhpMyAdmin is a webbased Open Source application, this application was created using a PHP program, the function of this application is to access the MySQL database.

According to Arief (2011), PhpMyAdmin is a GUI (Graphical User Interface) based application that is used to manage MySQL databases.

According to Prasetio (2012), PhpMyadmin is a webbased tool that is useful for managing MySQL databases.

Based on the opinions expressed above, it can be concluded that by using PhpMyAdmin, this application can help in accessing and managing the MySQL database.

\section{Systems Development Method}

According to Simarmata (2010), this section will discuss in general the process models that are often used in the software development community. The discussion will start with the waterfall model. In the process of designing this web-based inventory information system, using the Waterfall Method. That is because the waterfall method has clear, real and practical stages according to Al-Bahra (2009). If an error occurs, the Maintenance stage includes correction of errors not found in the previous step. The steps are as follows:

1. Data Collection, at this stage a complete and accurate search and collection of data and information is carried out by means of observation with several potential stakeholders in PT Telkom Access Samarinda area.

2. System Analysis, at this stage a direct observation was carried out on the current system regarding the management of ALPRO inventory data at PT Telkom Access Samarinda area.

3. System Design, at this stage the proposed system design is carried out regarding the management of inventory data using UML modeling, such as use case diagrams, activity diagrams, and sequence diagrams.

4. System Making, at this stage the creation of a Webbased application is based on the proposed system design.

5. System Testing, at this stage testing of the system that has been made.

Implementation and Maintenance, the implementation is carried out directly at PT Telkom Access Samarinda area and maintenance is carried out by checking data and applications regularly and if there is damage immediately repaired.

\section{RESEARCH METHODS}

A. Use case Diagram

Use case diagram ALPRO's Project Monitoring and Management System can be seen in the figure below.

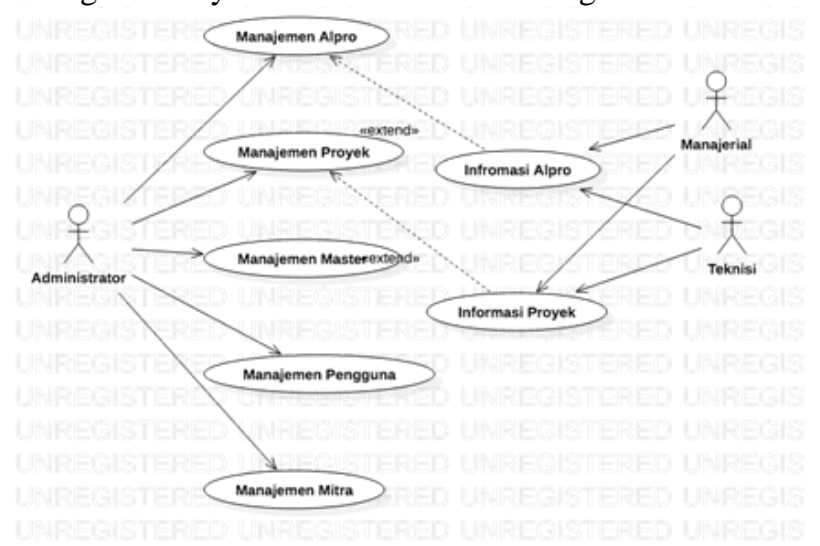

Picture. 1. Use case System Diagram

\section{B. Activity Diagram}

Activity the diagram for the ALPRO Project Monitoring and Management System for each relevant user can be seen in the section below.

\section{ALPRO Management By Administrator}

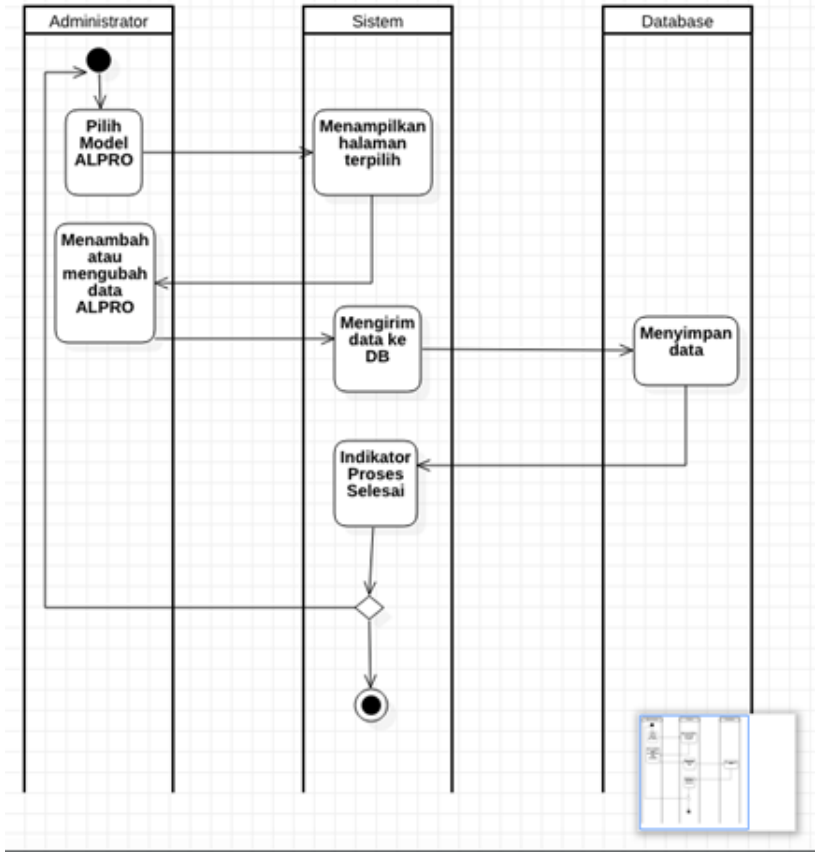

Picture. 2. Activity Diagram of ALPRO Management by Administrator 
2. Project Management by the Administrator

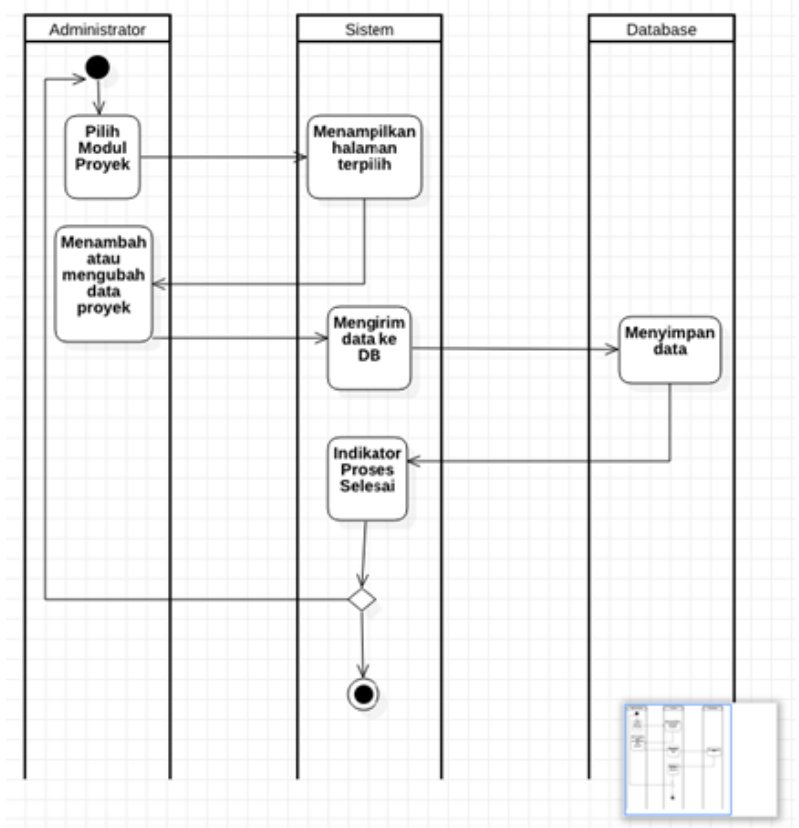

Picture. 3. Activity diagram of Project Management By Administrator

3. Master Management By Administrator

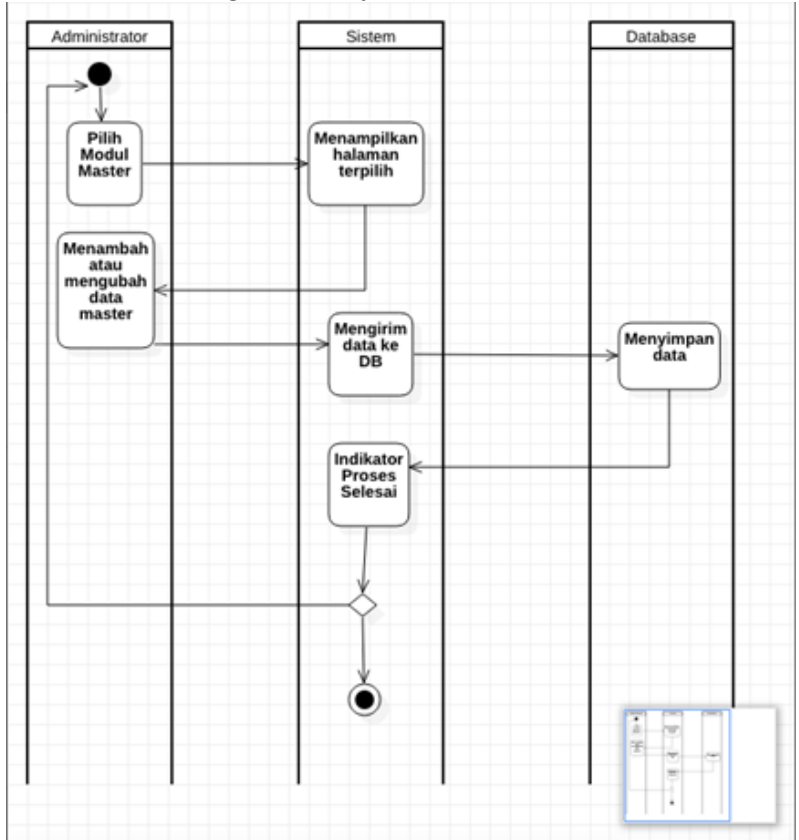

Picture. 4. Activity diagram of Master Management by Administrator
4. User Management By Administrator

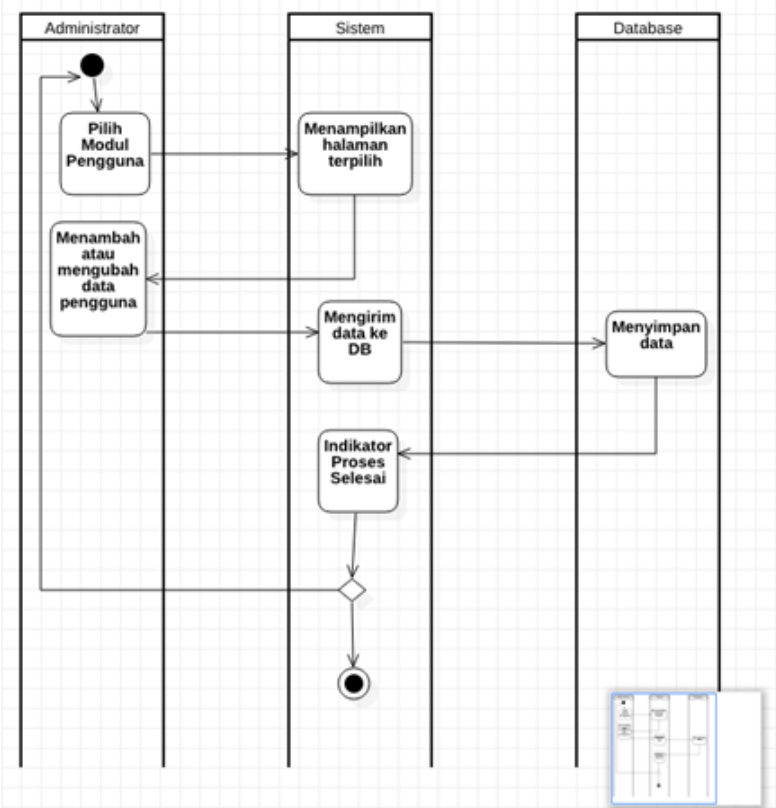

Picture. 5. User Management Activity Diagram by Administrator

5. Partner Management By Administrator

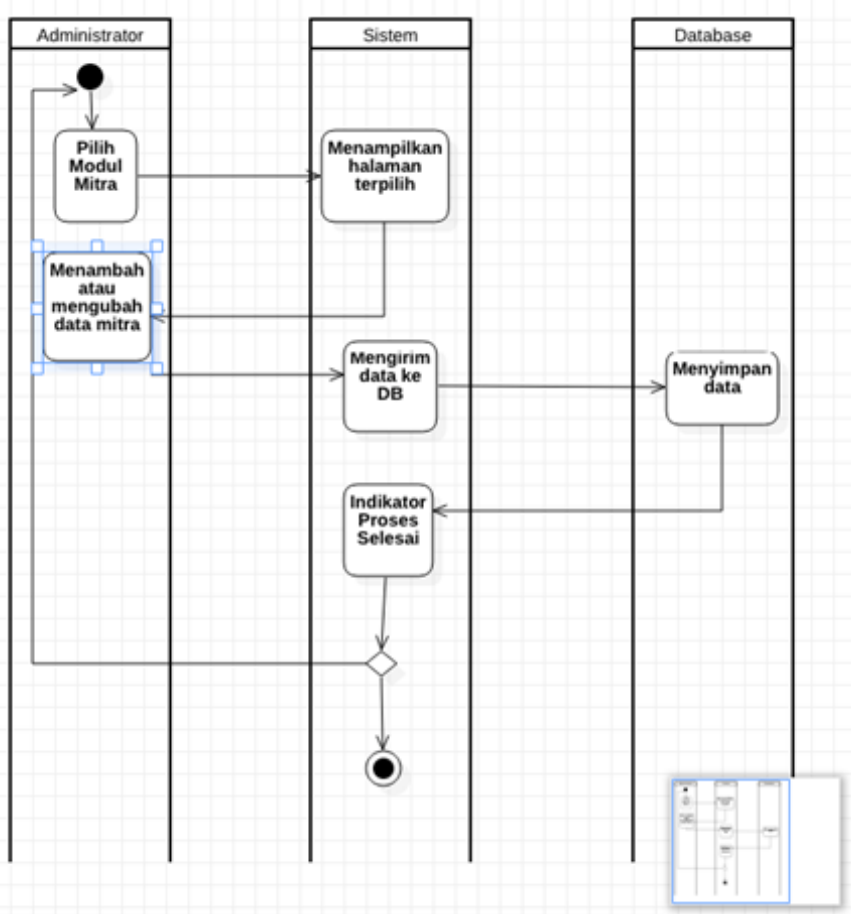

Picture. 6. Activity Diagram Partner Management By Administrator 
6. ALPRO Information By Managerial

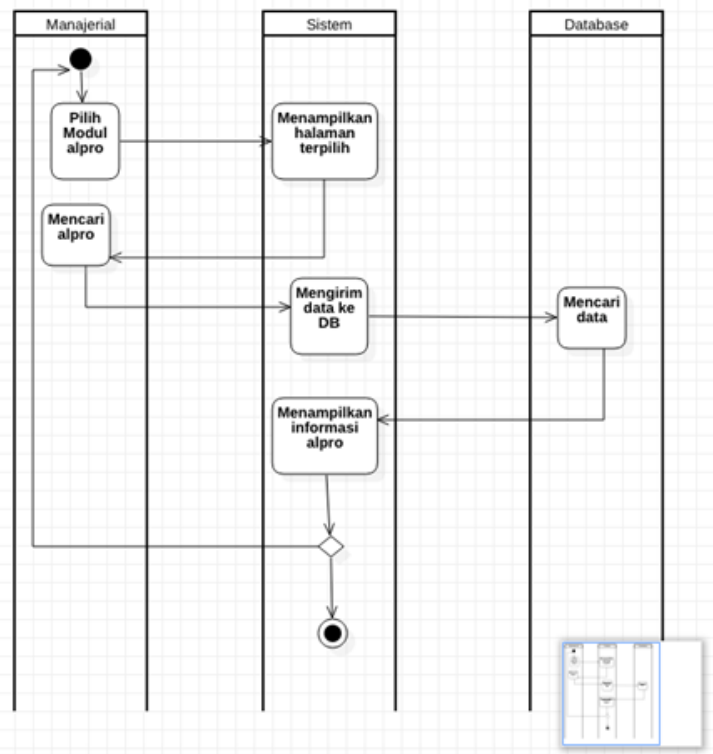

Picture. 7. Activity Diagram of ALPRO Information by Managerial

7. Project Information By Managerial

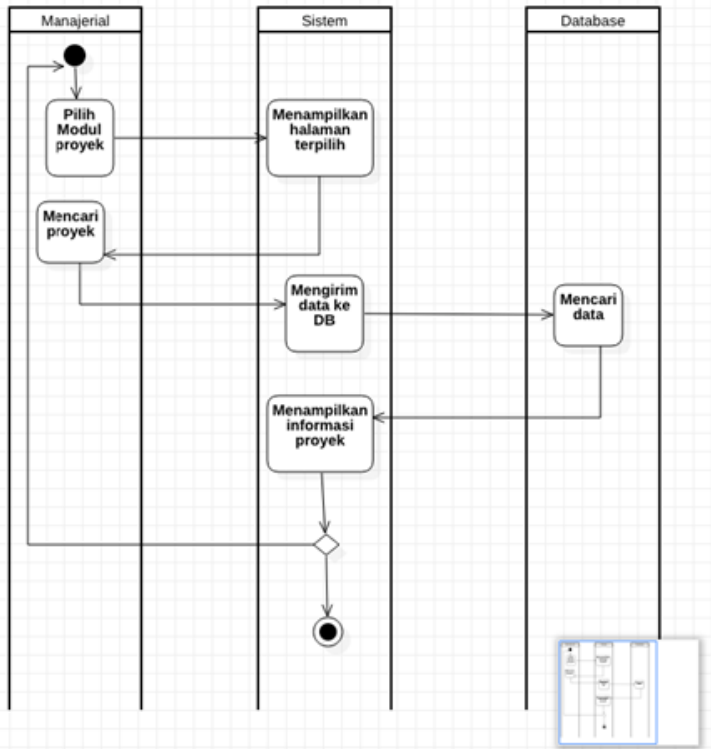

Picture. 8. Activity Diagram of Project Information By Managerial

8. ALPRO Information by Technicians

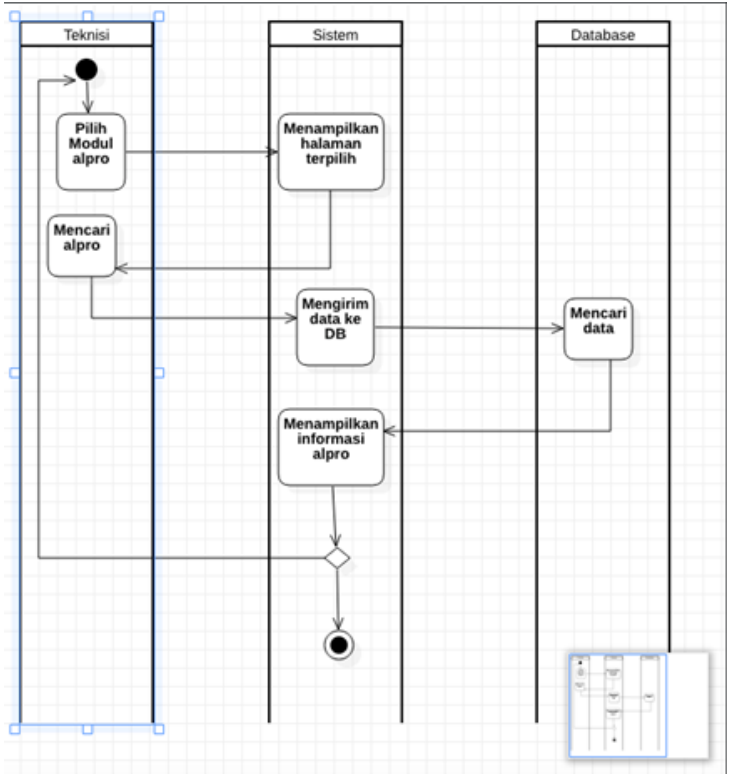

Picture. 9. ALPRO Information Activity Diagram by Technicians

\section{Class Diagram}

Class diagram for this system can also be seen in the image listed below.

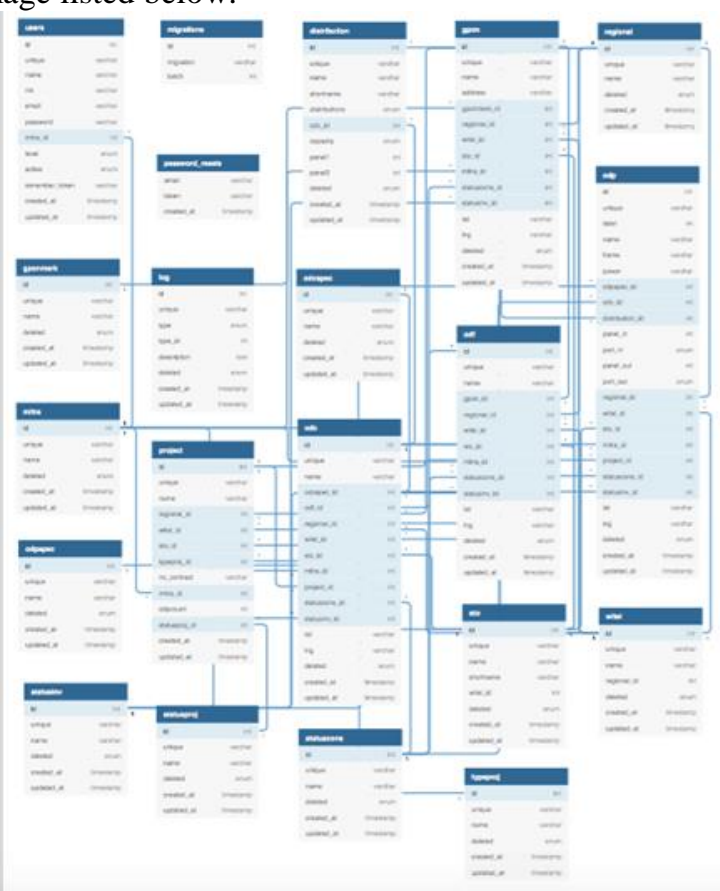

Picture. 10. Class System Diagrams 


\section{RESULT AND DISCUSSION}

1. Login page

The Login page is the first page that appears when the system is trying to be accessed, where the user enters the NIK and Password as the username and password on the system, as shown below.

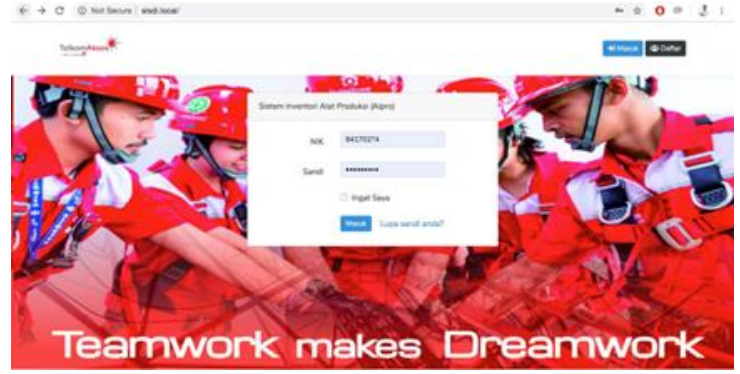

Picture. 11. Login page

\section{Home / Dashboard}

The main page / dashboard is a page that appears after a successful login process, where here can be seen all the menus / features contained in the system, as for the appearance of this page as shown below.

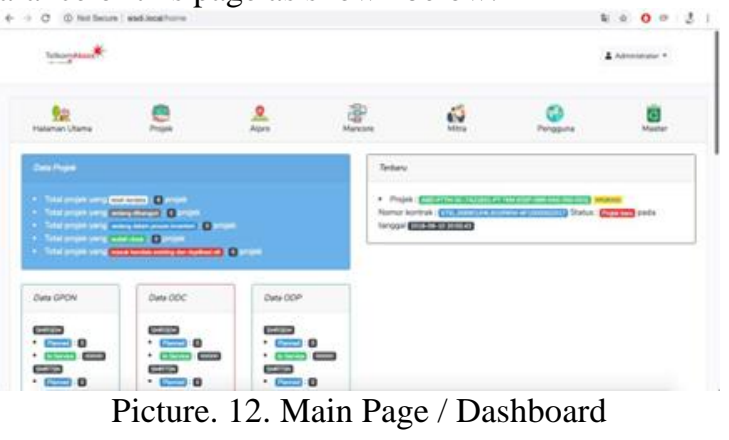

\section{ODP / New Project Booking Page}

This page is a page that is accessed if there is a new project development, of course there is the booking ODP process, it also looks like the image below.

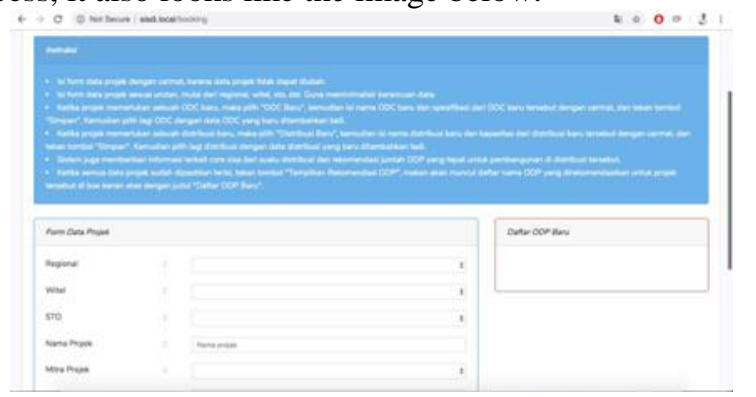

Picture. 13. ODP Booking page

4. ALPRO Management page

The ALPRO management page itself consists of GPON, ODF, ODC and ODP. Following is the display for each Telkom Group production equipment.

\section{1) GPON}

Is a page display for adding, deleting and changing GPON and also a page that contains GPON data

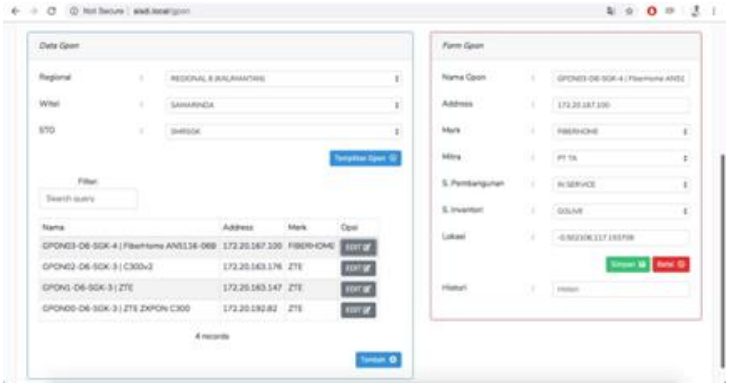

Picture. 14. GPON page

2) $\mathrm{ODF}$

Is a page display for adding, deleting and changing ODF and also a page that contains ODF data.

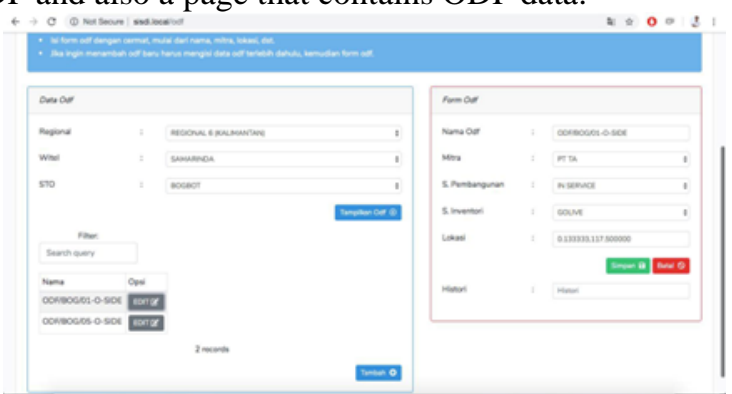

Picture. 15. page ODF

3) ODC

Is a page display for adding, removing and changing ODCs and also a page that contains ODC data.

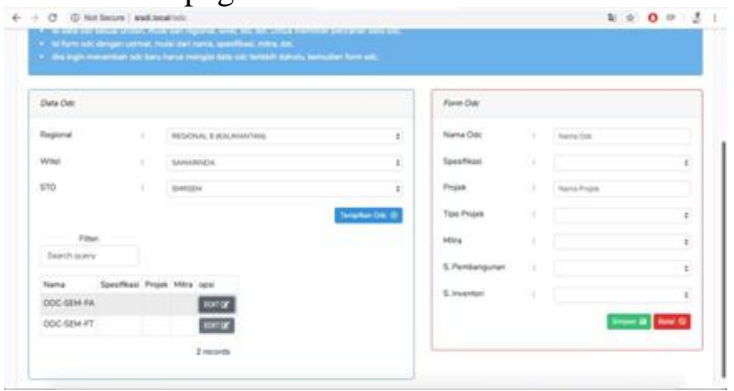

Picture. 16. page ODC

4) ODP

It is a page view for adding, deleting and changing ODP and is also a page that contains ODP data.

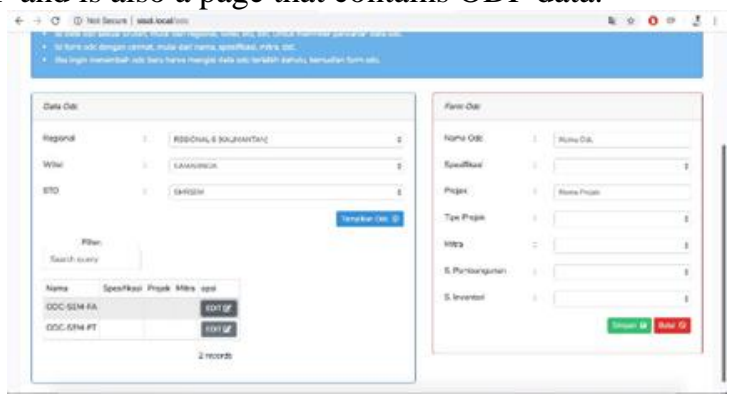

Picture. 17 ODP page

\section{Master Data Management page}

The Master Data Management page is a page that contains master data on the system, such as regional data, retail data, data STO, distribution data, etc. 


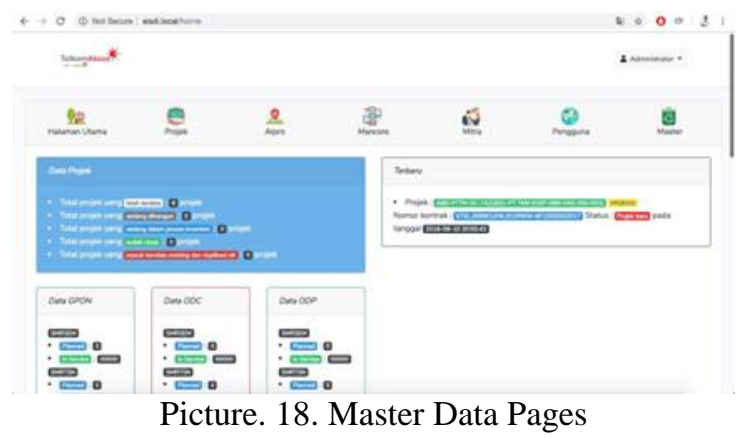

6. Distribution Management Page

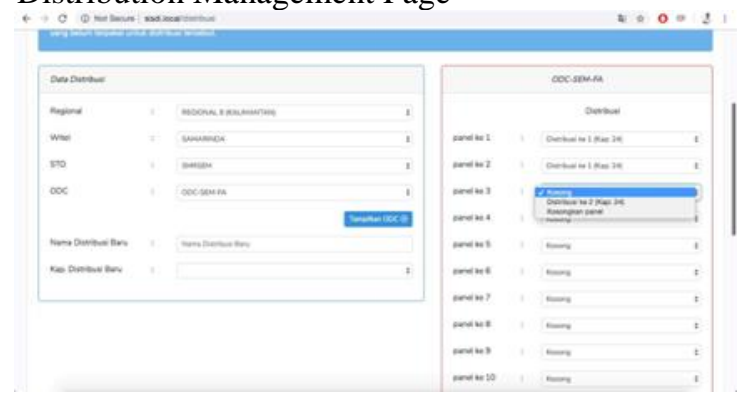

Picture. 19. Distribution Page

\section{CONCLUSION}

With this system, management can obtain information about each project and ALPR without having to wait for the SDI unit to answer questions in the telegram group. It is hoped that the process of inputting project data and production tools can be much faster than through a collection of spread sheets on Google Drive. Do not make technicians in the field waiting for a response for so long, especially at work breaks, evenings and holidays because maybe SDI friends are away from the keyboard.

\section{REFERENCE}

Anhar. 2010, Guide to Mastering PHP \& MySQL Autodidact. Jakarta: Mediakita.

Amsler. 2009, Performance monitoring: guidance for the modern workplace. Supervision, 70, 12-19.

Arief. M. Rudyanto, 2011, Dynamic Web Programming Using PHP \& MySQL. Yogyakarta: Andi.

Judge. Lukmanul. 2009, Shortcut to Become a PHP Master. Yogyakarta: Lokomedia.

Suyanto. AsepHerman. 2007, Step by Step Web Design: Theory and Practices. Ed. 1. Yogyakarta: Andi.

Jogiyanto. HM. 2009, Information Technology Systems. Yogyakarta: Andi.

Kadir. Abdul 2011, jQuery and PHP Smart Books for beginners. Yogyakarta: MediaKom.

Simarmata. Janner. 2010, Software Engineering. Yogyakarta: Andi.

PT Telkom Akses. About Us: Operations Service Areas. (Telkom Access). http://telkomakses.co.id/tentangkami/w wilayah-layanan-operasi/. Accessed May 27 2019. 